\title{
Quantificação de depósitos em folhas de trapoeraba com diferentes tipos de pontas de pulverização
}

\author{
Rodolfo Gonçalves Pereira ${ }^{1}$ \\ Thiago Barbosa Gonçalves da Silva² \\ Acácio Aparecido Anunciação ${ }^{3}$ \\ Wellington Hipólito dos Santos ${ }^{4}$ \\ Gustavo Rabelo Botrel Miranda5 \\ Alberto Donizete Alves ${ }^{6}$ \\ Raul Henrique Sartori ${ }^{7}$
}

\section{Resumo}

Com o objetivo de verificar o melhor modelo de pontas de pulverização hidráulica para a quantificação de depósitos em folhas de Commelina benghalensis L., foi desenvolvido um experimento, em março de 2012 no IFSULDEMINAS - Campus Muzambinho/MG, em lavoura de café da cultivar catuaí, com espaçamento de 3,7m x 1,0m. O delineamento utilizado foi em blocos ao acaso (DBC), com quatro tratamentos distribuídos em cinco blocos, onde foi avaliado o depósito de calda em folhas de trapoeraba. A solução marcadora era composta pelo corante azul brilhante (FD\&C n 1 ) a $0,15 \%$ $(\mathrm{p} / \mathrm{v})$ e os tratamentos - tipos de pontas de pulverização - foram: leque duplo (modelo TJ-60 11002 VS); leque comum (modelo ADI 11002); indução de ar (modelo ADIA Magno 11002); e cônico vazio (modelo J-4) - todos acoplados a pulverizador costal pressurizado $\left(\mathrm{CO}_{2}\right)$, utilizando barra com 2 bicos espaçados em $50 \mathrm{~cm}$ e altura de $40 \mathrm{~cm}$ do alvo biológico. As parcelas foram constituídas de 5 metros de comprimento por 1 metro de largura e, após a aplicação, foram coletadas 5 folhas de trapoeraba de cada parcela, que foram acondicionadas em sacos plásticos para serem lavadas e medidas posteriormente. A solução resultante foi analisada por espectrofotômetro a $630 \mathrm{~nm}$, quando se determinou o volume depositado nas folhas em $\mu \mathrm{L} \mathrm{cm}^{-2}$. Os valores obtidos foram submetidos à análise de variância pelo teste $\mathrm{F}$, e as médias, comparadas pelo teste de Tukey, ao nível de $5 \%$ de probabilidade, realizado pelo software SISVAR 4.3. Conclui-se que não há diferença significativa para deposição de calda em folhas de $C$. benghalensis L. para as pontas utilizadas.

Palavras-chave: Commelina benghalensis L. Corante. Tecnologia de aplicação

\footnotetext{
$\overline{1}$ Instituto Federal do Sul de Minas - Campus Muzambinho, bacharel do curso de Tecnologia em Cafeicultura. rodolfotecnologo@yahoo. com.br

2 Instituto Federal do Sul de Minas - Campus Muzambinho, bacharel do curso de Tecnologia em Cafeicultura. mediplanplanejamento@ hotmail.com

3 Instituto Federal do Sul de Minas - Campus Muzambinho, bacharel do curso de Tecnologia em Cafeicultura. acacioanunciacao@hotmail.com

4 Instituto Federal do Sul de Minas - Campus Muzambinho, bacharel do curso de Tecnologia em Cafeicultura. wellingtonhipolitodossantos@gmail.com

5 Instituto Federal do Sul de Minas - Campus Muzambinho, professor EBTT. grbmiranda@gmail.com

6 Instituto Federal do Sul de Minas - Campus Muzambinho, professor EBTT. albertoalves@milbr.net

7 Instituto Federal do Sul de Minas - Campus Muzambinho, professor EBTT.raulsartori@yahoo.com.br
} 


\section{Introdução}

No Brasil, a cafeicultura passou por relevantes mudanças geográficas e estruturais e, alternadamente, por momentos de crise e pujança, sempre mantendo sua importância relativa para 0 desenvolvimento brasileiro (RUFINO et al., 2010).

A produção e o desenvolvimento da atividade cafeeira são influenciados por uma série de fatores, entre os quais destacam-se as pragas, as doenças, a infestação de plantas daninhas, as adversidades climáticas e a dificuldade de mão de obra. Para permanecer na atividade, os produtores devem, cada vez mais, se atualizar e tecnificar, otimizando as atividades agrícolas com as novas tecnologias.

A geração de tecnologia na aplicação de herbicidas é extremamente rápida; entretanto, na cafeicultura as práticas utilizadas são antigas, ou seja, desatualizadas no âmbito de melhorias no uso desses recursos, tais como: escolha do equipamento, calibragem e tipo de pontas, que são de fundamental importância para a aplicação de agroquímicos. Portanto, o domínio da tecnologia de aplicação mostra-se fundamental para o aumento da eficiência do produto e a diminuição da contaminação do aplicador e do ambiente, bem como para a redução dos custos nas aplicações (BAUER; PEREIRA, 2005).

Para muitos produtores, a ponta de pulverização é apenas mais uma peça do conjunto de aplicação, sem muita importância. Para Christofoletti (1999), o bico de pulverização é o conjunto de peças colocado no final do circuito hidráulico, através do qual a calda é emitida para fora da máquina. Esse conjunto é composto de várias partes, das quais a ponta de pulverização é, sem dúvida, a mais importante, regulando a vazão, o tamanho das gotas e a forma do jato emitido.

Na maioria das vezes, dá-se muita importância ao produto fitossanitário a ser aplicado e pouca à técnica de aplicação. Não basta conhecer o produto a ser aplicado, também é fundamental conhecer a forma de aplicação (CUNHA et al., 2003).

No campo, observa-se desperdício de energia e, consequentemente, de recursos financeiros, muitas vezes, por causa do mau uso da tecnologia de aplicação, principalmente no que diz respeito às pontas de pulverização, que quando utilizadas com negligência podem distribuir o produto de forma ineficaz e não controlar as plantas daninhas, o que constitui um contrassenso, já que os produtos estão chegando a preços cada vez mais altos para o produtor. Assim, o conhecimento das condições de trabalho e o desempenho das pontas de pulverização são fundamentais quando se busca uma aplicação adequada, eficiente e econômica (CHRISTOFOLETTI, 1999).

Com isso, a associação do mau uso de técnicas de aplicação com uso indiscriminado de herbicidas acelera o processo de desenvolvimento de resistências em plantas daninhas.

A trapoeraba pertence à família Commelinaceae e possui folhas subpecioladas, ovoides, com bases atenuadas e ápices obtusos a agudos, de cor verde clara e com vilosidade em ambas as faces. O tamanho das folhas e das plantas varia muito em função das condições ambientais; o comprimento varia de 2 a $10 \mathrm{~cm}$ de comprimento por $3 \mathrm{~cm}$ de largura. As espatas de Commelina benghalensis L. são brevipedunculadas, triangulares e agrupadas no ápice do ramo (SANTOS et al., 2002).

A C. benghalensis L. é uma espécie de difícil controle, que pode causar diversos prejuízos na produção de café, principalmente na fase jovem da lavoura, sendo muito comum observar situações de escape. Um dos motivos para isso acontecer é a proteção que as bainhas exercem sobre as gemas, o que dificulta a penetração de calda nessas plantas (BLANCO, 2010).

O trabalho tem por objetivo a quantificação de depósitos retidos em folhas de trapoeraba em diferentes modelos de pontas de pulverização. 


\section{Material e métodos}

O experimento foi desenvolvido no Instituto Federal de Educação, Ciência e Tecnologia do Sul de Minas Gerais - Campus Muzambinho/MG, no dia 24/03/2012, em lavoura de café da cultivar Catuaí 144/9 vermelho, com 12 anos, estande de 2.700 plantas por hectare.

O delineamento experimental utilizado foi em blocos ao acaso (DBC), com cinco repetições, sendo quatro tratamentos definidos por diferentes tipos de pontas hidráulicas de pulverização: ponta leque duplo (modelo TJ-60 11002 VS); ponta leque comum (modelo ADI 11002); ponta com indução de ar (modelo ADIA Magno 11002); ponta cônico vazio (modelo J-4), todas acopladas a pulverizador costal manual pressurizado $\left(\mathrm{CO}_{2}\right)$.

Para avaliar quantitativamente os depósitos decorrentes das pulverizações com as diferentes pontas de pulverização hidráulica, foi preparada uma solução marcadora composta pelo corante azul brilhante (FD\&C no 1) a 0,15\% (p/v) (PALLADINI, 2000). Foi utilizada essa solução marcadora para a avaliação quantitativa do volume de calda depositado nas folhas de trapoeraba.

As parcelas foram constituídas de 5 metros de comprimento por 1 metro de largura. 0 local escolhido para constituição das parcelas foi uma área em que a planta daninha predominante era a C. benghalensis. A pulverização foi feita no período da tarde, com pulverizador costal pressurizado $\left(\mathrm{CO}_{2}\right)$, utilizando barra com 2 bicos espaçados na largura de $50 \mathrm{~cm}$ e altura de $40 \mathrm{~cm}$ do alvo biológico. 0 volume de calda aplicado foi calibrado para o consumo de $200 \mathrm{~L} \mathrm{ha}^{-1}$.

Os dados meteorológicos (temperatura, umidade relativa do ar e velocidade do vento), durante a aplicação da calda de pulverização, foram registrados por um termo higrômetro (Modelo HT-3003) e anemômetro (Modelo AM-4201), ambos da marca Lutron, posicionados a dois metros de altura da superfície do solo, conforme adotado por Scudeler et al. (2004).

Após a aplicação da solução marcadora, foram coletadas 5 folhas de trapoeraba de cada parcela, utilizando luva cirúrgica e pinça, para inseri-las em sacos plásticos identificados, a fim de evitar perda dos corantes no ato da coleta. Após a coleta, o material foi levado para o laboratório de Bromatologia e Água do IFSULDEMINAS - Campus Muzambinho.

Cada amostra recebeu $100 \mathrm{~mL}$ de água destilada, mantida sob agitação por 30 segundos, para a remoção do traçador. A solução resultante foi colocada em recipientes de vidros e mantida sob refrigeração $\left(8 \pm 3^{\circ} \mathrm{C}\right)$. Após esse procedimento, os depósitos foram quantificados por um espectrofotômetro da marca FEMTO, modelo 700S, pela leitura da absorbância no comprimento de onda de 630 nanômetros.

Os valores de absorbância obtidos pelo espectrofotômetro proporcionaram a sua transformação em ppm (mg. $\mathrm{L}^{-1}$ ), de acordo com o coeficiente angular da curva-padrão estabelecida pelas diluições das amostras $(1 / 25,1 / 50,1 / 100,1 / 200,1 / 500,1 / 1000,1 / 2000,1 / 5000,1 / 10000)$ de cada calda de pulverização coletada no campo.

Como a concentração da calda foi a mesma em todos os volumes, verificou-se a mesma equação $\left(y=0,0718 e^{0,7564 x}\right)$ para todos os tratamentos, independente do valor da leitura da absorbância de cada volume, obtendo-se o valor da concentração em ppm do corante azul brilhante, a partir da substituição do valor $X$ da equação, pela leitura da absorbância da amostra aferida no espectrofotômetro.

Após a remoção do corante, mediu-se a área foliar das folhas de trapoeraba com a fórmula proposta por Huerta (1962) para folhas de cafeeiro, utilizada em folhas de trapoeraba por ter folhas de formato semelhante. Assim, a área foliar foi calculada de acordo com a fórmula $A F=C * L * 0,6666$, 
onde:

$\mathrm{AF}=$ Área foliar em centímetro quadrado $\left(\mathrm{cm}^{2}\right)$;

$\mathrm{C}=$ Comprimento da folha em centímetro $(\mathrm{cm})$;

$\mathrm{L}=$ Maior largura da folha $(\mathrm{cm})$;

$0,6666=$ Constante

As soluções de água e corante provindas da extração das amostras de trapoeraba foram lidas em espectrofotômetro, com o comprimento de onda de 630 nanômetros, determinando-se o volume depositado nas folhas por meio da seguinte equação:

$\mathrm{Ci} * \mathrm{Vi}=\mathrm{Cf} * \mathrm{Vf}$

onde:

Ci = Concentração inicial da calda (1500 ppm);

$\mathrm{Vi}=$ Volume inicial a ser calculado;

$\mathrm{Cf}=$ Concentração final que corresponde à concentração encontrada na leitura do espectrofotômetro;

$\mathrm{Vf}=$ Volume utilizado para lavar as folhas.

Após a determinação de volume depositado, calculou-se a deposição em microlitros $(\mu \mathrm{L})$ de calda por centímetro quadrado $\left(\mathrm{cm}^{2}\right)$ de superfície foliar. Os valores obtidos, referentes ao acúmulo de depósito em folhas, foram submetidos à análise de variância pelo teste $F$, e as médias comparadas pelo teste de Tukey ao nível de $5 \%$ de probabilidade, realizada pelo software de análises estatísticas SISVAR 4.3 (FERREIRA, 2011).

\section{Resultados e discussão}

No decorrer do experimento, a temperatura variou de $23,9^{\circ} \mathrm{C}$ a $25,2^{\circ} \mathrm{C}$, a umidade relativa do ar de $64 \%$ a $69,8 \%$ e a velocidade do vento de $0 \mathrm{~km} / \mathrm{h}$ a $0,5 \mathrm{~km} / \mathrm{h}$ (Tabela 1 ).

Tabela 1. Condições meteorológicas verificadas durante a pulverização. Muzambinho-MG , 2012.

\begin{tabular}{ccccc}
\hline Tratamento & $\begin{array}{c}\text { Início da aplicação } \\
(\mathrm{h})\end{array}$ & Temperatura $\left({ }^{\circ} \mathrm{C}\right)$ & $\begin{array}{c}\text { Umidade relativa } \\
(\text { UR\% })\end{array}$ & $\begin{array}{c}\text { Velocidade do vento } \\
\left(\mathrm{Km} \mathrm{h}^{-1}\right)\end{array}$ \\
\hline Leque duplo & $16: 17$ & 24,8 a 25,3 & 64,0 a 66,4 & 0,3 a 0,5 \\
Leque comum & $16: 37$ & 24,6 a 25,2 & 65,2 a 67,5 & 0,0 \\
Indução de ar & $16: 47$ & 23,9 a 24,5 & 67,8 a 68,3 & $<0,3$ \\
Cônico vazio & $16: 57$ & 23,8 a 24,0 & 69,8 a 70,8 & $<0,4$ \\
\hline
\end{tabular}

Fonte: Elaboração dos autores.

A quantificação do corante marcador possibilitou o estabelecimento da seguinte equação (y $=0,0718 \mathrm{e}^{0,7564 \mathrm{x}}$ ), com coeficiente de determinação $\mathrm{R}^{2}=0,9989$ (Figura 1 ) para todos os tipos de pontas, onde:

$X=$ leitura da densidade óptica (absorbância);

$\mathrm{Y}=$ concentração em ppm dos tratamentos durante a pulverização. 


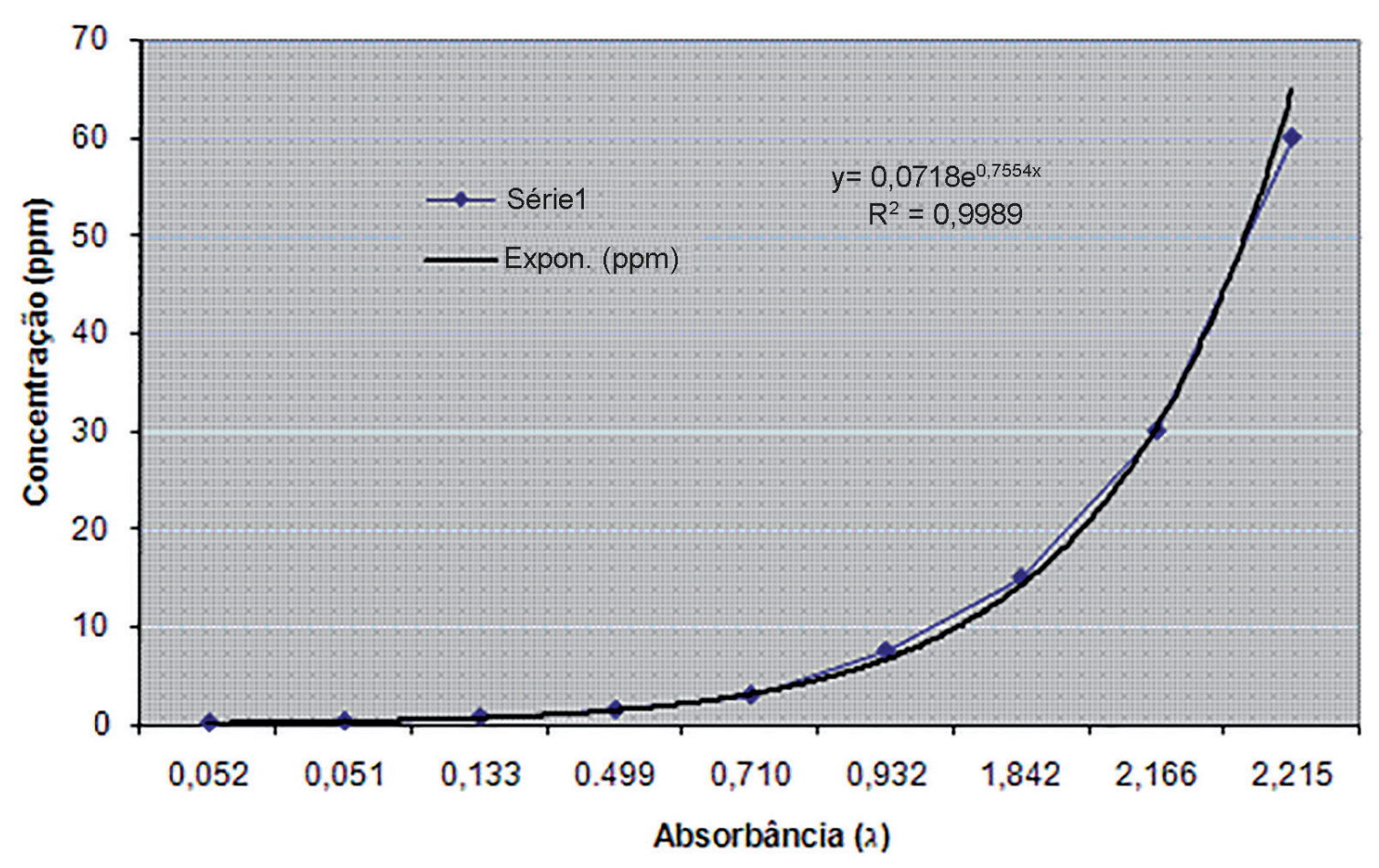

Figura 1. Curva de leitura de absorbância para inferir a concentração das amostras de calda.

Fonte: Elaboração dos autores.

Observa-se na Figura 1 um alto valor do coeficiente de correlação $\left(R^{2}\right)$ para os valores de absorbância lidos no espectrofotômetro, em função da alteração de concentração (mg. $\mathrm{L}^{-1}$ ).

Os valores médios de depósitos $\left(\mu \mathrm{L} . \mathrm{cm}^{-2}\right)$, em folhas de trapoeraba, proporcionados pela pulverização de vários tipos de pontas de pulverização hidráulica, não diferiram (Tabela 2).

Tabela 2. Valores médios de depósitos $\left(\mu \mathrm{L} . \mathrm{cm}^{-2}\right)$ após pulverização com diferentes modelos de pontas de pulverização em folhas de trapoeraba. Muzambinho, 2012.

\begin{tabular}{ll}
\hline Tratamento & Volume/área foliar $\left(\mu \mathrm{L} \mathrm{cm}^{-2}\right)$ \\
\hline Leque duplo & $0,378 \mathrm{a}$ \\
Leque comum & $0,349 \mathrm{a}$ \\
Indução de ar & $0,368 \mathrm{a}$ \\
Cônico vazio & $0,371 \mathrm{a}$ \\
\hline CV\% & 13,57 \\
\hline
\end{tabular}

Médias seguidas pela mesma letra minúscula na coluna não diferem entre si pelo teste de Tukey a $5 \%$ de significância.

Fonte: Elaboração dos autores.

Essa igualdade estatística do acúmulo de depósitos em folhas de trapoeraba pode ser atribuída ao fato de que as pontas possuem a mesma vazão, ou seja, todas têm vazão de 0,2 gal min-1.

$\mathrm{O}$ fato de o modelo das pontas testadas configurarem características completamente diferentes entre si, como tamanhos de gotas, tamanho da ponta, tubulação interna da ponta, entre outras características, não parece definir a quantidade de volume acumulado em folhas de trapoeraba, mesmo utilizando a ponta cônico vazio, diferente do observado por Costa et al. (2012), em que o tamanho e a densidade das gotas e as perdas para o solo e por deriva influenciaram na deposição da calda. A seleção correta das pontas de pulverização é uma forma de se obter maior deposição do ingrediente ativo sobre o alvo desejado. 
A ponta de jato cônico vazio gera gotas de menor tamanho que, auxiliadas pelo movimento rotacionado do jato, penetram no dossel da cultura, aumentando a deposição sobre o alvo, o que proporciona, consequentemente, maior densidade de gotas (CUNHA et al., 2004).

Barcellos et al. (1998), estudando a deposição de gotas no dossel da cultura da soja, também não encontraram diferenças significativas na deposição de gotas da ponta jato cônico vazio em relação às pontas de jato plano.

Essa igualdade nos depósitos das pontas de pulverização pode ser atribuída às diferenças na formação dos jatos de pulverização dos diferentes modelos de pontas, já que as pontas do tipo cônico vazio possuem uma abertura do ângulo de pulverização de $80^{\circ}$, enquanto as demais pontas de pulverização tinham abertura do ângulo de $110^{\circ}$.

Tais diferenças nos ângulos de pulverização das pontas não seriam importantes se não tivesse sido utilizada barra de duas pontas de pulverização, visto que essa barra proporciona uma necessidade de sobreposição para que ocorra melhor formação da pulverização. Caso a sobreposição seja inadequada, ocorre o comprometimento da pulverização ou ineficácia do defensivo agrícola.

Realmente, para pontas de pulverização tipo leque $110^{\circ}$ de abertura, é correto utilizar a barra de pulverização mais baixa, em torno de $30 \mathrm{~cm}$, objetivando manter a faixa de deposição contínua. Entretanto, nesse tipo de ponta de pulverização, a deposição da calda é direta no alvo, enquanto com pontas tipo cônico, a deposição ocorre de forma helicoidal, o que permite maior mobilidade das gotas e, por isso, possibilita manter a mesma altura de barra para ambos os tipos de pontas de pulverização.

Para a maioria dos herbicidas indicados no controle da trapoeraba, recomenda-se a ponta de jato leque para se obter maior cobertura de aplicação, o que se traduz em eficiência de controle (ANDREI, 2009).

Características anatômicas e morfológicas de C. benghalensis e Commelina diffusa podem estar envolvidas na eficiência do herbicida glyphosate. C. benghalensis apresenta, na epiderme adaxial, 10,66 pelos $\mathrm{mm}^{-2}$, o que pode favorecer a absorção do herbicida (SANTOS et al., 2002). Trata-se do mesmo fator que pode influenciar a retenção da calda e do corante, o que justifica a igualdade estatística de depósitos retidos na superfície foliar de trapoeraba.

Apesar dessa igualdade, no momento da aplicação, foi observado que a pulverização realizada com a ponta de leque duplo TJ60 proporcionou maior volume de gotas pequenas na névoa, o que, aparentemente, formaria uma melhor distribuição de gotas em cobertura de folhas de trapoeraba. Entretanto, não se verificou diferença significativa no resultado, conforme se vê na Tabela 2.

Rodrigues et al. (2010) mostraram que a ponta que proporcionou maiores depósitos em plantas de feijão foi a ponta de leque plano simples, comparada às de jato plano duplo e cônico vazio. Para depósitos em Brachiaria plantaginea, a ponta TJ 60 proporcionou maior depósito, superior às pontas leque simples e cônico vazio. Esses resultados diferem dos do presente trabalho.

Boschini et al. (2008) avaliaram a deposição de calda em folhas de soja com diferentes pontas de pulverização (leque simples, duplo leque, duplo leque com indução de ar e cone vazio) e verificaram maior deposição quando foi utilizada a ponta de jato duplo no terço superior; já no terço mediano e inferior, a melhor deposição foi encontrada utilizando a ponta cone vazio.

Outros trabalhos têm mostrado que a deposição da calda de pulverização não sofre influência pela utilização de diferentes tipos de pontas. Vale citar Costa et al. (2012), segundo os quais, na avaliação da deposição de glyphosate com diferentes tipos de pontas de pulverização na dessecação de plantas de Panicum maxicum cv. Mombaça, todos os tratamentos foram eficientes, independente da ponta utilizada. Barcellos et al. (2005), igualmente, verificaram que, em avaliações feitas aos 7 dias 
após a pulverização, não se evidenciaram efeitos significativos no controle geral das plantas daninhas (Commelina sp, Ipomea sp, Richardia brasiliensis, Blainvillea latifólia e Portulaca oleracea) que pudessem ser atribuídos aos diferentes tipos de pontas de pulverização.

\title{
Considerações finais
}

Vale lembrar que, em uma pulverização com volumes de calda menores, a tecnologia de aplicação torna-se mais crítica, razão pela qual as deposições poderão ser diferentes das obtidas neste trabalho, necessitando de novos estudos para comprovar tal hipótese.

\section{Conclusão}

Os resultados da pesquisa aqui expostos levam à conclusão de que o acúmulo de depósitos de pulverização em folhas de Commelina benghalensis L. foi semelhante em todas as pontas de pulverização utilizadas, sem diferença significativa.

\section{Evaluation of deposition of syrup on spiderwort leaves according to different types of spray tips}

\begin{abstract}
In order to verify the best model of hydraulic spray nozzles for quantification of deposits on Commelina benghalensis L. leaves, an experiment was conducted on March 2012, at IFSULDEMINAS - Muzambinho/MG, in Catuaí coffee crop, spaced $3.7 \mathrm{~m} \times 1.0 \mathrm{~m}$. The design was in randomized blocks (RBC) with four treatments distributed in five blocks, which assessed spray deposit on spiderwort leaves. The solution was Brilliant Blue dye (FD\&C no 1) $0.15 \%(w / v)$ marker, and treatments were kinds of nozzle spray: double fan (TJ-60 11002 model VS); common range (ADI 11002 model); air induction (AIXR 11002 model) and hollow cone (J-4 model) - all of them sprayed with a knapsack sprayer $\left(\mathrm{CO}_{2}\right)$, using bar with two nozzles spaced at $50 \mathrm{~cm}$ and $40 \mathrm{~cm}$ height of the target chemical. The plots were $5 \mathrm{~m}$ long by $1.00 \mathrm{~m}$ wide, and after applying, 5 leaves were collected from each spiderwort plot, which were placed in plastic bags to be washed and measured subsequently. The resulting solution was analyzed by spectrophotometer at $630 \mathrm{~nm}$, by which the deposited volume was determined in $\mu \mathrm{L}$ $\mathrm{cm}^{2}$ leaves. The values obtained were subjected to analysis of variance by $\mathrm{F}$ test and averages were compared by Tukey test at 5\% probability carried out by software SISVAR 4.3. We concluded that there is no significant difference in spray deposition on $C$. benghalensis L. leaves for the tips used.
\end{abstract}

Keywords - Application technology. Commelina benghalensis L. Dye

\section{Referências}

ANDREI, E. Compêndio de defensivos agrícolas: guia prático de produtos fitossanitários para uso agrícola. 8. ed. São Paulo: Organização Andrei, 2009. 1378p. 
BARCELLOS, L. C.; ALMEIDA, R. A.; LEÃO, P. G. F.; CARVALHO, Y. Bicos de pulverização na aplicação de herbicidas pós emergente na cultura da soja. Pesquisa Agropecuária Tropical, Goiânia, v. 35, n. 2, p. 85-91, abr. 2005.

BARCELLOS, L. C.; CARVALHO, Y.C.; SILVA A. L. Estudo sobre a penetração de gotas no dossel da cultura da soja [Glycine Max . (L.) Merill]. Engenharia na Agricultura, Viçosa, v. 6, n. 2, p. 81-94, 1998.

BAUER, F. C.; PEREIRA, F. A. R. Fitossanidade e produção agrícola. In: BAUER, F. C.; VARGAS JUNIOR, F. M. (Coords.) Produção e gestão agroindustrial. Campo Grande: Editora Uniderp, 2005. p. 23-48.

BLANCO, F. M. G. Trapoeraba - uma planta daninha de difícil controle. Centro Experimental Central, n. 132, 2010.

BOSCHINI, L.; CONTIERO, R. L.; MACEDO, E. K. J.; GUIMARÃES, V. F. Avaliação da deposição da calda de pulverização em função da vazão e do tipo de bico hidráulico na cultura da soja. Acta Scientiarum Agronomy, v. 30, n. 2, p. 171-175, 2008.

CHRISTOFOLETTI, J. C. Considerações sobre a deriva nas pulverizações agrícolas e seu controle. São Paulo: Teejet South América, 1999. 15 p.

COSTA, N. V.; Deposição de glyphosate com diferentes pontas de pulverização na dessecação de plantas de Panicum maximum. Revista Brasileira de Herbicidas, v. 11, n. 1, p. 96-107, jan./abr. 2012.

CUNHA, J. P. A. R.; TEIXEIRA, M. M.; COURY, J. R.; FERREIRA, L. R. Avaliação de estratégias para redução da deriva de agrotóxicos em pulverizações. Planta Daninha, Viçosa, v. 21, n. 2, p. 325-332, 2003.

CUNHA, J. P. A. R.; TEIXEIRA, M. M.; VIEIRA, R. F.; FERNANDES, H. C.; COURY, J. R. Espectro de gotas de bicos de pulverização hidráulicos de jato plano e de jato cônico vazio. Pesquisa Agropecuaria Brasileira, Brasília, v. 39, n. 10, p. 977-985, out. 2004.

FERREIRA, D. F. Sisvar: a computer statistical analysis system. Ciência e Agrotecnologia (UFLA), v. 35, n. 6, p. 1039-1042, 2011.

HUERTA, S. A. Comparación de métodos de laboratorio y de campo para medir el área foliar del cafeto. Cenicafé, Caldas, v. 13, n. 1, p. 33-42, ene./mar. 1962.

PALLADINI, L. A. Metodologia para avaliação da deposição em pulverizações. 2000. 111f. Tese (Doutorado em Agronomia/Proteção de Plantas) - Faculdade de Ciências Agronômicas, Universidade Estadual Paulista, Botucatu, 2000.

RODRIGUES, A. C. P.; MARTINS, D.; COSTA, N. V.; CARDOSO, L. A.; DOMINGOS, V. D. Variáveis qualitativas da pulverização em feijão, Bidens pilosa e Brachiaria plantaginea. Ciência e Agrotecnologia, Lavras, v. 34, n. 3, maio/jun. 2010.

RUFINO, J. L. S.; SILVEIRA, V. S.; RIBEIRO JUNIOR, A. C. Caracterização da Cafeicultura de Montanha de Minas Gerais. Belo Horizonte: INAES, 2010. 300p. 
SANTOS, I. C.; MEIRA, R. M. S. A.; FERREIRA, F. A.; SANTOS, L. D. T.; MIRANDA, G. V. Caracteres anatômicos de duas espécies de trapoeraba e a eficiência do glyphosate. Planta daninha, Viçosa, V. 20, n. 1, abr. 2002 .

SCUDELER, F.; BAUER, F. C.; RAETANO, C. G. Ângulo da barra e ponta de pulverização na deposição da pulverização em soja. In: SIMPÓSIO INTERNACIONAL DE TECNOLOGIA DE APLICAÇÃO DE AGROTÓXICOS, 3, 2004, Botucatu, SP. Anais... Botucatu: FEPAF, 2004. P. 13-16.

\section{Histórico editorial}

Submetido em: 16/09/2014

Aceito em: 11/02/2015 